\title{
Os foodies na arena sociológica
}

\section{The foodies in sociological arena}

\author{
Elaine de Azevedo ${ }^{1}$ \\ PGCS/UFEShttps://orcid.org/0000-0002-9637-6111 \\ DOI: https://doi.org/10.21680/1982-1662.2019v2n25ID18333
}

\section{Resumo}

Esta pesquisa conceitual problematiza o conceito de 'foodie', neologismo cunhado pela crítica gastronômica Gael Greene e popularizado pelos jornalistas Ann Barr e Paul Levy em seu The Official Foodie Handbook publicado na década de 1990. O fenômeno é explorado com muito mais vigor através das lentes de jornalistas em colunas gastronômicas e ainda pouco discutido nas Ciências Sociais. 0 estudo revela o potencial sociológico dessa temática que transpassa categorias de análise como cultura alimentar, classe, gênero, consumo, estilo de vida, hedonismo e ética.

Palavras-chaves: Foodie. Alimento. Gastronomia. Estilo de vida.

\begin{abstract}
This conceptual research problematizes the concept of foodie, neologism coined by the gastronomic critic Gael Greene and popularized by the journalists Ann Barr and Paul Levy in his The Official Foodie Handbook, published in the decade of 1990. The phenomenon is explored with much more vigor through the lenses of journalists in gastronomic columns and little discussed in the Social Sciences. The study reveals the sociological potential of this thematic that transpasses categories of analysis as class, gender, consumption, lifestyle, hedonism and ethics.
\end{abstract}

Keywords: Foodies. Food. Gastronomy. Lifestyle.

\footnotetext{
${ }^{1}$ Email: elainepeled@gmail.com
} 
Sou o Rodrigo. Um Foodie. Pois. Não encontro palavra em Português tão simples quanto esta. Que explica tudo. Um Foodie é um apaixonado nato por tudo o que sejam iguarias. Por tudo o que sejam ingredientes. Por tudo o que sejam formas de cozinhar e de aprender sobre cozinha. Desde o mais simples ao mais especial! Tudo é importante. Sejam um cachorro quente ou caviar com lavagante. Sejam um grande Chef com estrelas ou o Cozinheiro do restaurante lá do bairro que serve deliciosos pratos do dia. Tudo é motivo de paixão: Cozinhar, os Ingredientes, as facas e os tachos, os livros de receitas ou de técnicas culinárias e toda a tralha que se pode encontrar dentro de uma cozinha. Um Foodie faz viagens gastronómicas com o propósito de conhecer uma mesa. Adora fazer jantares para os amigos. Fala de vinhos e de comida, e de mais vinhos e mais comida a noite inteira. Sabe quem é o Chef que cozinha no Restaurante " $X$ " e quem é o Sub-Chef do Restaurante " $Z$ ". Tal e qual como quem gosta de Futebol. Um Foodie sabe e adora o que é bom. Discute o melhor dos melhores. O melhor Restaurante da cidade, o melhor arroz de cabidela do mundo, a melhor mercearia, o melhor isto ou o melhor aquilo. Desde que tenha algo para se comer ou provar. E faz isso tudo com uma convicção quase religiosa. Quase obsessão e muita paixão $(. . .)^{2}$

O foodie - como palavra, conceito, pessoa - apareceu no início dos anos 80. Não há desde então uma tradução para o neologismo em nenhuma outra língua. Um foodie é um foodie em qualquer país - seus membros são tão semelhantes entre si quanto diferentes de todos os outros, fala Bryan R. Myers (2011), escritor e professor americano de estudos internacionais. E, como se pode ver no relato acima, um português também usa o termo literal.

Sob a ansiedade por expressões que expliquem novos comportamentos sociais, o escritor Gael Greene usou pela primeira vez o termo em uma resenha de restaurante em Nova York. Mas foram os jornalistas Ann Barr e Paul Levy que o popularizaram e legitimaram através de uma publicação: The Official Foodie Handbook, de 1984. São tantas tentativas de (auto) definição que o conceito demanda atenção sociológica. Menos pelo que deseja ser e mais pelas ambições e anseios que envolve e pelas discussões que suscita.

Barr e Levy (1984) explicaram que o foodie não é um gourmet, já que ela não precisa ter um estilo refinado nem ser um especialista ou ter um paladar apurado. Ela também não é gourmand, pois não precisa ter um grande apetite. Josephine Livingstone (2019) resume que o foodie come para atender às demandas de seu corpo do pescoço para cima, não do pescoço para baixo. Mente, boca, alma: é lá que vive o foodie. Outra diferença do foodie para os gourmands e gourmets é que, além de

\footnotetext{
${ }^{2}$ Texto disponível em: http://www.foodie.pt/bem-vindo-ao-foodie-pt. Acesso em: 22 Mar 2019.
} 
gostar de comer bem e ter domínio sobre a arte culinária, os foodies são consumistas e gastam fortunas nesse hobby de gente refinada. Grande parte dos foodies é formada por empresários, médicos, intelectuais (sim, no masculino já que a maioria deles é homem) que têm um interesse desmensurado com tudo que se relacione com comida. Procuram conhecer a origem dos ingredientes, o contexto histórico em que o prato surgiu e seu significado social. A comida é percebida como um solvente universal do intelecto; é assim também para quem tem a comida como objeto de estudo ou prática, mas nesse caso não é uma profissão.

A geração Yum é um tipo de versão juvenil dos foodies, igualmente obsessivos por comida e por receitas e experiências gastronômicas. Para Eve Turow (2015), esses jovens da geração millenials encontram nos prazeres sensoriais que a culinária oferece a privação sensorial que a era digital promove. E acrescenta que eles buscam na comida um senso de comunidade e pertencimento.

Apesar da recorrente crítica a superficialidade dos foodies, o estudo sociológico de Josée Johnston e Shyon Baumann (2014) ressalta que o interesse pela boa comida pode ser democrático e, como mostrou nosso foodie português, muitos dos adeptos estão interessados em todo tipo de comida - até mesmo aquela encontrada em paradas de caminhoneiros, sinalizam os autores - desde que seja boa. Ou seja, qualquer pessoa pode ser um foodie. Por outro lado, os dois autores canadenses endossam as premissas sociológicas já apontadas por Bourdieu ao mencionar que a comida funciona como uma fonte de distinção para as elites econômicas e culturais. A alegação dos autores é que a paisagem americana representa um cenário ideal para a busca de status, usada para alcançar distinção e reforçar as fronteiras sociais.

O que ocorre é que foodism tornou-se mais uma estratégia para manter privilégios e reproduzir as desigualdades sociais. Sob outra ambiguidade, Johnston e Baumann (2014) mostram que, enquanto algumas pessoas associam o fenômeno com esnobismo, elitismo ou a ausência de uma significativa conexão com a comida, outros percebem os foodies como amantes da boa comida e com o desejo de aprender mais sobre culinária e o comer. Além disso, os autores usam o foodism para criar uma teoria sobre o onivorismo cultural. Johnston e Baumann argumentam que os padrões de consumo foodie são onívoros como uma forma de negociar a tensão entre a busca de status e a inclusão democrática. Ou seja, ao selecionar uma ampla gama de possibilidades culinárias e legitimar suas escolhas como "autênticas ou exóticas", os 
foodies tentam escapar de serem julgados como “esnobes arbitrários”.

Nascimento (2005), sob certa ironia comum a muitos autores que discutem o fenômeno, cita reportagem do Jornal do Brasil descrevendo o foodie como aquele que:

(...) não bebe vinho, harmoniza. Só compra javali na barraca do Roberto no Mercado Municipal. Não gosta de seguir receita, porque cozinhar é uma necessidade de expressão. Em um jantar com um grupo, lança aqui e ali palavras como fantastique, magnifique, super. Visitou pelo menos três restaurantes três estrelas do Guia Michelin. Tem um avental branco com o seu nome bordado, um Larousse Gastronomique e um livro editado pela DBA. Cultiva ervas em vasinhos na varanda. Mistura foie-gras com chocolate. Ouve jazz enquanto cozinha. Só salga a comida com a flor de sal de Guérande. Se tem condições econômicas e espaço sobrando, o foodie tem uma segunda cozinha onde a empregada não entra. Para intelectualizar o hobby, cita frases de escritores sobre o prazer de comer. É capaz de gastar o valor de dois carros populares num fogão. Jamais usa caldo em tablete na cozinha e, sim, com os ossos da carne que está sendo preparada. Tem pelo menos uma panela de grife. Tem adega climatizada e entende de vinhos o suficiente para saber escolher qual combina melhor com cada prato. Distingue 15 tipos diferentes de arroz, 26 de azeite, 8 de melão, 9 de alface, 89 de macarrão e mais de 200 de queijo (p. 220).

Paul Levy, citado por Nascimento (2005), disse que três coisas importam para o foodie: saúde (para poder comer mais por mais tempo), dinheiro (para escolher o que comer sem ter de fazer contas) e o ponto de cozimento do peixe. No texto do The Guardian' Levy (2015) incorporou um aspecto patológico ao conceito ao mencionar que um foodie vive para comer e faz isso de forma obsessiva.

É verdade que os foodies cabem em um mundo em que a comida - assim como o sexo, o consumo, o esporte, a internet - tornou-se uma obsessão. Quando se discute obsessão por comida surge rapidamente a fixação por dietas - inumeráveis - e os alimentos da moda, como as superfoods ou os superalimentos definidos como alimentos ricos em fitoquímicos - micronutrientes antioxidantes ou outras classes de bioativos vegetais. Os alimentos que dessa categoria incluem sementes de chia e cânhamo, bagas de açaí, mirtilos, romãs, beterraba, soja, chá verde, bagas de goji, óleo de coco, salmão, chocolate escuro, cacau e couve na mesma ideia dos alimentos funcionais. Seu consumo se enquadra numa tendência normativa de alimentos por grupos afluentes que, impulsionados pela mídia e pela indústria de alimentos promovem um tipo de "empreendedorismo corporal que acaba por patologizar corpos não-conformes e produzem, por parte do consumidor, ansiedade corporal e uma relação dolorosa com a alimentação" (SIKKA, 2019, n.p). 
Mas o que interessa aqui é a obsessão por comida e culinária. Como menciona o jornalista e escritor Steven Pole (2012): “food is the new sex, drugs and religion”. Ele cita o crítico de comida Alex James que diz que "minha festa de 20 anos era pautada nas bebidas; a de 30 anos nas drogas e agora a de quarenta é na comida". Para Pole, a comida e a busca do prazer nos alimentos são novos vícios para a geração ecstasy. Uma droga hedônica mais segura e respeitável na forma de um tipo de psicose (alimentar) aprovada pela sociedade.

Vivemos a "era da comida", diz Steve Pole (2012). A cultura gastronômica nunca foi tão discutida - desde os intelectuais da gastronomia até os posts frequentes dos leigos e gastronautas nas mídias sociais. Os chefs são celebridades nos concorridos festivais de comida que substituem a efervescência dos antigos festivais de rock; o documentário de alimentos é um gênero de cinema; os livros mais vendidos estão na categoria “comida e bebida", inexistente antes de 1999; os restaurantes são templos gastronômicos onde os gurus cozinham e as receitas e os menus são promessas antecipadas de prazer. Pole (2012) cita o diálogo entre o romancista francês Alain Robbe-Grillet e seu amigo Roland Barthes que discutem o cardápio no restaurante como um "exercício abstrato de vocabulário", mais importante do que o consumo dos pratos em si, uma promessa sedutora de satisfação como uma nota promissória para o prazer futuro. Não é a toa que os garçons de restaurantes finos são especialmente treinados para descrever detalhadamente os pratos dos menus degustação. Nesse tipo de experiência na qual o cliente não lê previamente o que vai comer, o garçom provê o que Barthes chama de enquadramento linguístico que acontece de forma a alterar/ intensificar a experiência do comedor. Comemos também as sensações prometidas.

O mercado especializado colhe os lucros desse comportamento contemporâneo. Companhias de turismo oferecem viagens enogastronômico-culturais, cujo programa inclui refeições e visitas a restaurantes tradicionais, a fazendas produtoras de alimentos típicos e vinícolas ou roteiros gastronômicos por diversas cidades, além de aulas de culinária para amadores em diferentes países. As compras dos foodies incluem louças e utensílios para cozinha, temperos e diários com impressões sobre restaurantes e descrição de pratos experimentados. Um comportamento foodie, pode inclusive ter influenciado o fato de a cozinha voltar a ser (depois da sua desqualificação do início da modernidade) um lugar privilegiado, de aventuras gastronômicas com biblioteca de livros de receitas, aparelhos de filmagem e uma 
infinidade de utensílios sofisticados onde os convidados são chamados a vivenciar experiências culinárias (NASCIMENTO, 2005).

\section{"Cruzada moral" contra o foodie-ism}

O processo de civilização do apetite cunhado por Norbert Elias e Stephen Mennel culmina na contemporaneidade com o que muitos dos autores aqui mobilizados chamam de foodie-ism (ou foodism). Steve Pole (2012) propõe, inclusive, um novíssimo termo - foodist - incorporando a ideologia do sufixo: como um racista, nudista, budista ou sexista, um foodist opera sob os conceitos de uma ideologia governante, vendo o mundo inteiro através das lentes "manchadas de gordura de um comedor militante". Mas talvez não seja necessário outro termo para dizer mais do mesmo. Para Pole (2012), a ideologia do foodism implica um desejo de "preencher um vazio espiritual e expressar nossa identidade via comida", repetindo ironicamente os anseios do jornalista Michael Pollan a que chama de "moderno cavaleiro de alimentos":

\footnotetext{
Seu célebre catecismo do foodism moderno, o Dilema do Onívoro, fala de comer com uma "plena consciência", e afirma que toda refeição tem seu "preço cármico"; termina com a declaração de que "o que estamos comendo nunca é nada mais ou menos que o corpo do mundo". E, assim, mastigar produtos de carne de porco se torna uma união sublime de si mesmo com o planeta, uma eucaristia de Gaia (POLE, 2012, n.p).
}

Pole (2012) se inspira na cruzada moral contra os foodies travada por Bryan R. Myers (2011) que problematiza a espiritualização da comida e critica as futilidade das semanas que antecedem o planeamento de um jantar perfeito ou as viagens dos foodies a Paris "para comprar queijo" ou ao Vietnam para experimentar o "pho perfeito". Além de levantar a questão da pertinência ética de manter o sacrifício de animais para o enlevo gastro-espiritual, Myers ironiza as referências espirituais de cozinheiros comparados a "deuses", de restaurantes relacionados a "templos", e da experiência de “chegar ao céu” e alcançar o "sagrado" diante de uma refeição "perfeita". A crucificação do foodism em Myers tem nomes e sobrenomes: o jornalista Michel Pollan, Kim Severson colunista de gastronomia do New York Times e os sociólogos Josée Johnston e Shyon Baumann que são, para o escritor, membros da própria subcultura que exaltam. 
Contestando a relação das experiências foodistas com o despertar espiritual, Myers (2011) foca sua crítica no consumo inconsciente da carne e no pecado da glutonaria. A gula, no entendimento original, não era necessariamente uma questão de comer demais; era o problema de estar excessivamente interessado em comida. 0 escritor cita Francine Prose que explica que o desejo desordenado por comida é que nos afasta do caminho da razão. Menciona também o teólogo Thomas Aquinas e o papa Gregory para quem a gula pode ser cometida de cinco formas diferentes, entre as quais a busca por alimentos sumptuosos ou o preparo exageradamente meticuloso dos alimentos. Neste sentido, todos os foodies modernos seriam glutões - ou pecadores, se é que a frugalidade alimentar os comove de alguma forma. 0 que se pode concluir é que a relação entre comer como um foodie e nutrir seu espírito é um erro de categoria tão grande como aquele que levou a igreja primitiva a definir gula como um pecado.

Uma das críticas mais ferozes aos foodies, veio logo após a edição do The Official Foodie Handbook, em 1985. Sob a expansão da política de austeridade e regulação econômica de Reagan, Angela Carter (1985) relaciona a prática dos foodies a um tipo de "esnobismo histérico" frente a fome que assola diferentes países. 0 livro seria um manual de etiqueta para uma classe social recém-emergente, os foodies de Reagan:

Uma das ironias resultantes da dicotomia entre o Norte e o Sul do nosso planeta é a aparição deste estranho pequeno livro, um vade mecum para um culto disseminado e desavergonhado da conspícua glutonaria nos países industrializados avançados, exatamente no momento em (...) oitocentos milhões de pessoas no mundo vivem em constante medo de morrer de fome (...) "Foodies", de acordo com Barr e Levy, são "filhos do boom do consumo" que consideram "comida uma arte, em um nível de pintura ou drama". (...) Esse volume, publicado nos EUA nos primeiros dias do Presidente Reagan, foi uma alegre lista de verificação dos atributos da classe média alta norteamericana, tão leve que dava a impressão de que não tinha coração algum (...) O livro era uma celebração mal disfarçada do esnobismo (...) e, sob sua superfície fina e irônica, não era nada mais nada menos que um manual de etiqueta para uma classe recém-emergente sob o governo Reaganomics. Ele instruiu os novos ricos sobre os hábitos e as maneiras dos milionários tradicionais de modo que eles pudessem passar despercebidos entre eles (...) a comida é a base deste novo esnobismo histérico. Circunstâncias econômicas muito especiais, reminiscentes da época do declínio do Império Romano e também do auge da Inglaterra eduardiana estabelecem a glutonaria como a marca de uma classe em ascensão. O Manual observa: "É preciso várias coisas para sustentar uma cultura dos foodies: lojas de alta classe, transporte rápido trazendo produtos frescos da terra, comedores bem pagos e esclarecidos que apoiarão restaurantes luxuosos, trabalhadores com salários mais baixos para fazer a comida. De repente, todos esses elementos estão presentes" (CARTER, 1985, n.p). 
Sua crítica se estende ao jornal The Guardian que, logo após a publicação do Manual, assume uma coluna semanal dedicada a gastronomia e ainda mais evidenciada do que o espaço relegado ao cinema e a literatura, aponta Carter:

A pocilga triunfante invadiu até mesmo as páginas do jornal The Guardian, até então sinônimo de sobriedade não-conformista. Em vez de sua modesta coluna de receitas e resenhas de restaurantes, o jornal agora ostenta uma página inteira semanal dedicada a comida e ao vinho uma vez; mais espaço do que os filmes, como costuma dar aos livros (CARTER, 1985, n.p).

Josephine Livingstone (2019) também endossa o caráter elitista do foodism ao levar em conta como a indústria de restaurantes finos se sobrepõe à comida caseira cujo efeito geral é de uma cultura que favorece o sexo masculino, o branco e o rico. Foodism, para ela, é largamente criado por pessoas brancas para pessoas brancas. Até mesmo as tentativas de diversificar a cultura gastronômica entre os foodies contêm uma marca perniciosa de exotismo e do colonialismo alimentar. A jornalista cita a artista Sukjong Hong que vê o foodism como "uma forma de consumo conspícuo que se disfarça". Para Hong, quando a comida é separada de sua função prática e do contexto cultural, torna-se uma propriedade da mídia colonialista utilizando uma linguagem oportunista de descoberta, valorização e autenticidade em torno de alimentos que não são da cultura dominante.

A comida autêntica é simples e tem raízes de vários tipos: via especificidade geográfica, conexão pessoal, a ligação histórica ou tradicional ou conexões étnicas, tanto para produtores como para consumidores de alimentos. Como a autenticidade, o exotismo é um elemento-chave do discurso gastronômico e dos foodies. 0 exotismo representa um interesse cosmopolita em ampliar o cânone da culinária e formar conexões interculturais, mas pode mascarar um discurso orientalista do outro e um processo de busca de status. O conhecimento de alimentos percebidos como autênticos ou exóticos requer um investimento de tempo e um conjunto de habilidades cognitivas e estéticas que geralmente acompanham o ensino superior e níveis de renda mais altos. É por isso que em vez de promover a democracia e igualdade, a autenticidade e o exotismo na gastronomia tendem a facilitar a distinção e perpetuação das hierarquias gustativas no discurso foodie como destacaram Johnston e Baumann (2009). 
Uma “visão reconciliatória" com os foodies

Apesar da provocação de Myers (2011) com relação a insensibilidade dos foodies frente ao sacrifício animal - inclusive de espécies em extinção - para satisfazer seu prazer gustatório utilizando as tradições, é perceptível que um verdadeiro foodie contemporâneo exprime uma preferência por carnes de animais criados livres e felizes, provenientes de fazendas locais de pequenos agricultores orgânicos.

Um paladar verdadeiramente refinado hoje rejeita o sabor da carne produzida sob confinamento, bem como o de vegetais contaminados por agrotóxicos, congelados e transportados por longas distâncias e, pela defesa dessas causas, os sociólogos canadenses Johnston e Baumann (2014) reconhecem um "certo" nível de politização dos foodies que podem afetar a consciência do comedor. Um "certo" porque tal politização caracteriza-se por uma atitude pseudo crítica em relação às implicações políticas do que e como a grande maioria da população come. Embora a alimentação seja, às vezes, enquadrada em termos políticos as preocupações ambientais, a pobreza, a segurança alimentar e a deterioração dos recursos naturais, não é a maneira como o alimento é discutido no discurso dominante dos foodies. A maior critica dos sociólogos é que quando as preocupações políticas são expressas, os foodies não se posicionam nem exigem mudanças estruturais e significativas, o que enfatiza sua incapacidade de comprometer a busca do prazer e da autoindulgência.

Talvez o que mova a maioria dos foodies continue a ser o sabor e o desejo de estar em sintonia com os novos modismos. Porém não há dúvidas de que a cultura gastronômica está agitando uma nova consciência das políticas sociais, minando alguns dos princípios não enunciados da cultura: que o gosto e o prazer são conceitos neutros e universais e que a cozinha é uma zona apolítica. Se os criadores do conceito escrevessem sobre ser um foodie em 2019, incorporariam certamente a interseção da cultura alimentar com política, raça, gênero e classe. A frase inicial do manual: "seja moderno - reverencie a comida", adquire outro significado hoje quando em que os chefs incorporam preocupações politicamente corretas nos seus cardápios.

O movimento Slow Food, no seu inicio na Itália, também atraiu o mesmo tipo de críticas: movimento elitista, que mantinha o fetichismo das mercadorias, a nostalgia e o ludismo culinário (DAVOLIO, F.; SASSATELLI, 2009). A agricultura orgânica ainda 
sofre essas críticas, especialmente em países com grandes diferenças de condições de acesso a alimentos de qualidade e a outras necessidades básicas. De forma geral, esses movimentos se politizaram, são percebidos como propostas de ativismo alimentar e incorporam conceitos de justiça social, de sustentabilidade ambiental, de patrimônio, segurança e soberania alimentar.

Vale ressaltar que denúncia de que os alimentos orgânicos são elitizados encobre uma situação muito mais complexa. Repetir que "alimentos de qualidade ou orgânicos são caros” acaba por desviar a cobrança da responsabilidade do Estado em melhorar a condição de pobreza extrema e de promover saúde e alimentos de qualidade como direitos básicos para todos os cidadãos. E isso depende de vontade política. Subsídio e financiamento equitativo aos agricultores familiares orgânicos frente aos grandes produtores rurais; inserção do alimento orgânico no mercado institucional (escolas, hospitais, prisões) garantindo a produção do agricultor; apoio para disseminação de pontos de venda e espaços públicos de comercialização direta; suporte para transporte, processamento e divulgação adequada do produto orgânico, além de apoio a pesquisas em universidades e instituições de pesquisa pública e informação à população são algumas das ações do Estado que podem facilitar o acesso a um alimento de qualidade superior para toda a população.

No Brasil, a aproximação dos chefs com os clamores do ativismo alimentar como a promoção dos alimentos orgânicos, da agricultura familiar, do movimento sem terra, da reforma agrária e do veganismo - espalhou-se antes mesmo da conscientização dos especialistas da área da saúde que, de forma geral, ainda discutem pouco tais questões em seus currículos acadêmicos. Muitos chefs cozinham de graça para apoiar movimentos de ocupação em grandes cidades, participam de festivais gastronômicos regionais e Banquetaços a favor da "comida de verdade" ou se posicionam contra governos de extrema direita - mesmo que isso os afaste de seus etilizados clientes ${ }^{3}$ (DÓRIA; AZEVEDO, 2019). Nos EUA, o chef Tunde Wey assume o que chama de gastronomia político-performática, mesclando a culinária com uma crítica vigorosa sobre a gentrificação e a desigualdade racial. Em 2018, ele organizou um

\footnotetext{
${ }^{3}$ Menção ao fato que aconteceu durante a campanha \#elenao, de oposição a candidatura de Jair Bolsonaro, assumida na rede social privada da chef Helena Rizzo do restaurante paulistano Mani. Seus clientes protestaram nas mídias sociais contra seu posicionamento político e prometeram boicotar o restaurante. Mais informações em: https://f5.folha.uol.com.br/celebridades/2018/10/clientes-fazemcampanha-contra-restaurante-mani-apos-chef-publicar-foto-contraria-a-bolsonaro.shtml. Acesso em 30 Mar 2019.
} 
evento chamado Hot Chicken Shit, em Nashville, onde ele cobrou US\$ 1 mil para os comensais brancos por quatro pedaços de frango, enquanto os negros comeram de graça. Em Nova Orleans, Wey abriu uma lanchonete na qual os brancos são convidados a pagar duas vezes e meia a mais por um prato de comida do que por negros, 0 equivalente aproximado da disparidade de renda entre os dois grupos. Em várias outras cidades, ele organiza jantares onde a comida e a bebida são um motivo de facilitar alguns tipos de conversas que os americanos sempre tentam evitar. Sobre racismo, por exemplo (MARTIN, 2019).

No Brasil, sob a tentativa de diluir a problemática da separação da experiência gastronômica do seu contexto cultural surgem iniciativas como a do Instituto lacitata de Cultura Alimentar, em Belém, no Pará, que se define como um espaço de circulação da produção da cultura alimentar e de produtos da sociobiodiversidade. Lá ocorrem vendas desses produtos com os quais são feitas as refeições ali servidas. 0 instituto faz parte do projeto Cultura Alimentar Tradicional Amazônica da ONG Amazônia Viva e promove argumentações que problematizam a relação entre gastronomia e cultura. Tornou-se um espaço de reflexão e transmissão de conhecimentos sobre a culinária indígena do Brasil; uma luta de "contracolonização alimentar", como provoca a ativista alimentar Tainá Marajoara ao mencionar o interesse culturalmente descontextualizado dos chefs do sudeste acerca dos alimentos identitários da Amazônia. O movimento não deve estar interessado em associar-se ao foodism, mas certamente a proposta é um fermento para implementar a discussão sobre a autenticidade e o exotismo alimentar supramencionada.

Nessa mesma onda de resgate da "brasilianidade alimentar", o sociólogo da alimentação Carlos Alberto Doria e o chef Marcelo Corrêa Bastos fazem uma refinada pesquisa histórica da culinária caipira no centro sul do Brasil, região chamada de Paulistânia (DORIA; BASTOS, 2018).

Mesmo diante dessas experiências “gastropolíticas', Livingstone (2019) reconhece a dificuldade de definir política nesse âmbito, uma vez que a cultura alimentar é coextensiva a cultura humana. A comida é praticamente sinônimo de vida e quando um comportamento é cotidiano é muito mais difícil politizá-lo. A jornalista cita a feminista Betty Friedan que tomou a vida cotidiana para mostrar que o “normal" é político e, da mesma forma que o feminismo, o comer político pode tornar-se uma realidade para todos. 


\section{Considerações finais}

As preocupações sócio ambientais dos foodies relacionadas a produção de alimentos podem obliterar o potencial negativo do seu elitismo - principal fonte de ceticismo sobre seu efetivo potencial político. Tal fato é considerado um elemento de conflito social no que Davolio e Sassatelli (2009) chamam de visão reconciliatória da política alimentar.

Essas duas sociólogas do consumo ressaltam que apesar de Johnston e Baumann (2009) reconhecerem que os elementos contra culturais dos anos sessenta e setenta vêm sendo retomados e traduzidos em um formato esteticamente compatível pelo foodism convencional, os sociólogos canadenses não conseguiram perceber a amplidão da mudança política do foodism contemporâneo, nem tentaram encaixá-lo na onda do consumerismo político de Micheletti ou de investimento político do consumidor de alimentos.

O posicionamento do discurso foodist no campo mais amplo da representação dos alimentos ainda merece ser explorado, se considerarmos a variedade de formatos de politização que precisam ser compreendidos.

É preciso estar atento as influências que as preferências desse grupo (e de todos os formatos de ativismo alimentar) podem exercer sobre o futuro do sistema agroalimentar.

Estudos empíricos sobre os foodies podem ser sociologicamente estimulantes na medida em que inserem a comida como uma elemento de fusão e separação entre grupos. O foodism como subcultura pode ajudar a compreender melhor a relação entre as escolhas alimentares, as iniquidades sociais e os estilos de vida, as tensões entre o prazer, a culpa e a necessidade, além das contradições que envolvem categorias de análise nos estudos da sociologia da alimentação como classe, gênero, consumo, hedonismo e ética.

\section{Referências}

BARR, A. LEVY, P. The Official Foodie Handbook. London: Ebury Press, 1984. 
CARTER, A. Noovs' hoovs in the trough, 1985. Disponível em: <https: //www.lrb.co.uk/v07/n01/angela-carter/noovs-hoovs-in-the-trough>. Acesso em: 24 Mar 2019.

DAVOLIO, F. SASSATELLI, R. Comment on Josée Johnston and Shyon Baumann. Foodies Aesthetics and their Reconciliatory View of Food Politics. Sociologica, n. 1, 2009. Disponível em: <https://www.rivisteweb.it/download/article/10.2383/29566>. Acesso em: 29 Mar 2019.

DORIA, C.A.; AZEVEDO, E. Banquetaço: Ativismo alimentar e a construção de novas formas de expressão política, 2019. Disponível Em: <https://diplomatique.org.br/banquetaco-ativismo-alimentar/>. Acesso em: $2 \mathrm{Abr}$ 2019.

DORIA, C.A.; BASTOS, M.C. A Culinária Caipira da Paulistânia. São Paulo: Editora Três Estrelas, 2018.

JOHNSTON, J.; BAUMANN, S. Foodies: Democracy and Distinction in the Gourmet Foodscape. London: Routledge, 2009.

LEVY, P. Ann Barr, 2015. Disponível em:

<https: / / www.independent.co.uk/news/people/news/ann-barr-writer-and-editorwho-in-the-1980s-identified-the-new-social-groups-of-sloane-rangers-and10227334.html>. Acesso em: 6 Mar 2019.

LIVINGSTONE, J. What Was the Foodie? 2019. Disponível em:

<https://newrepublic.com/article/153335/foodie>. Acesso em: 3 Mar 2019.

MARTIN, B. The Provocations of Chef Tunde Wey, 2019. Disponível em: <https://www.gq.com/story/chef-tunde-wey-profile>. Acesso em: 23 Mar 2019.

MYERS, B. The Moral Crusade Against Foodies, 2011. Disponível em: <https://www.theatlantic.com/magazine/archive/2011/03/the-moral-crusadeagainst-foodies/308370/>. Acesso em: 5 Mar 2019.

NASCIMENTO, A.B. Comida, prazeres, gozos e transgressões. Salvador: EDUFBA, 2007.

POLE, S. Let's start foodies backlash, 2012. Disponível em: <https: / / www.theguardian.com/books/2012/sep/28/lets-start-foodie-backlash>. Acesso em 20 Mar 2019.

SIKKA, T. The contradictions of a superfood consumerism in a postfeminist, neoliberal world. Food, Culture and Society [no prelo, 2019]. Disponível em: <https: / / www.tandfonline.com/doi/full/10.1080/15528014.2019.1580534?scroll=top\& needAccess=true>. Acesso em: 23 Mar 2019.

TUROW, Eve. Taste of Generation Yum: How the Millennial Generation's Love for Organic Fare, Celebrity Chefs, and Microbrews Will Make or Break the Future of Food. Kindle E-book, 2015. 